\title{
Cadaver dissection study of the pectoral nerves for feasibility in brachial plexus injuries
}

\author{
Srijana $\mathbf{M .}^{1}$, Srikanth R. ${ }^{2}$ \\ ${ }^{1}$ Dr. M. Srijana, Assistant Professor, ${ }^{2}$ Dr. R. Srikanth, Professor and HOD; both authors are affiliated with Nizam's \\ Institute of Medical Sciences, Hyderabad, Telangana, India.
}

Address for Correspondence: Dr. M. Srijana, Email: srijanamuppireddy14@gmail.com

\begin{abstract}
Injury to upper trunk of Brachial Plexus is the most common injury pattern. Major functions affected those of supra scapular nerve (SSN), axillary nerve $(\mathrm{AXN})$ and musculocutaneous nerve $(\mathrm{MCN})$ which resulting dysfunction of elbow flexion shoulder abduction and internal rotation. Intra-plexal nerve donors are more efficacious than extra-plexal nerve donors and expendable.
\end{abstract}

Keywords: Medial Pectoral Nerve, Musculocutaneous Nerve, Axillary Nerve, Brachial Plexus

\section{Introduction}

Injury to upper trunk of Brachial Plexus is the most common injury pattern. Major functions affected those of supra scapular nerve ( $\mathrm{SSN})$, axillary nerve (AXN) and musculocutaneous nerve (MCN) which resulting dysfunction of elbow flexion shoulder abduction and internal rotation. The most common target nerves that need neurotisation in adult traumatic brachial plexus injuries are the MCN, AXN and the SSN; if sufficient donors are available then the LTN and uncommonly the SAN need to be neurotised also

Intra-plexal nerve donors are more efficacious than extraplexal nerve donors and expendable donors that have been used are as follows:

In the neck - nerve to subclavius
Below the clavicle - lateral and medial pectoral nerves and thoracodorsal nerve

In the axilla $\quad-$ ulnar, median and radial nerve

The pectoralis major muscle has innervations from all the roots of the brachial plexus and hence at least the medial or lateral pectoral nerve could be available as an axon source, since target neurotisation is ideally done without the use of an interposition nerve graft and hence it is essential to do a cadaver study to determine how much of the donor nerve would be available and based on this finding which nerves could be the potential targets. The purpose of the cadaveric study is to determine the feasibility of using the medial pectoral nerve as a donor for neurotisation in partial plexus injuries.

\section{Materials and Methods}

The present cadaveric study was carried out in the autopsy room of forensic department at our institute between the years 2010 - 2011. The dissection was carried out on either side of the body in 3 cadavers and only on one side on 4 cadavers. From Seven fresh cadavers, ten Brachial Plexuses were dissected. Brachial plexus exploration was performed in standard fashion. An incision is made along the deltopectoral groove from the clavicle to the axilla and then continued distally to the medial aspect of the arm (Fig 1). Entire surface of pectoralis muscle was exposed after skin and subcutaneous tissue was reflected. Through the interval between clavicular and sternocostal parts the emergence of Thoracoacromial vessels identified. The under surface of muscle is freed from subjacent planes to expose the vessels and nerves (Fig $2 \& 3$ ). The

Manuscript received $14^{\text {th }}$ October 2016

Reviewed: $26^{\text {th }}$ October 2016

Author Corrected: $11^{\text {th }}$ November 2016

Accepted for Publication $23^{\text {rd }}$ November 2016 
humeral insertion of pectoralis major muscle was transected the medial and lateral pectoral nerves were explored and traced upto their origin from medial and lateral cords.

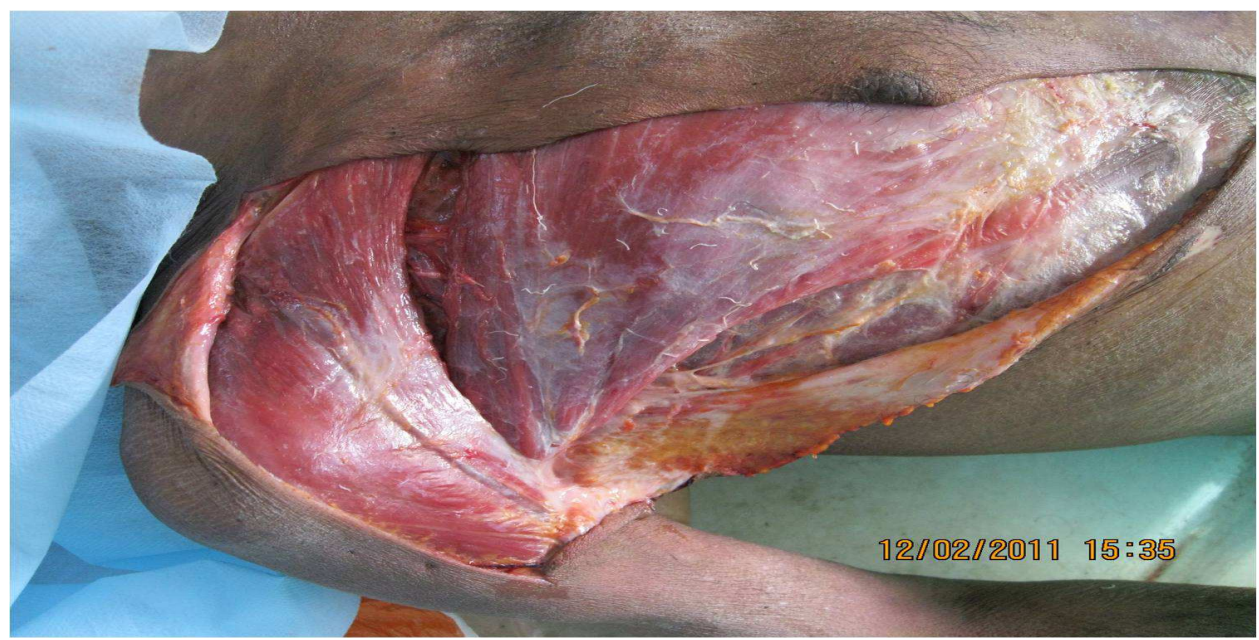

Fig-1: Incision marking

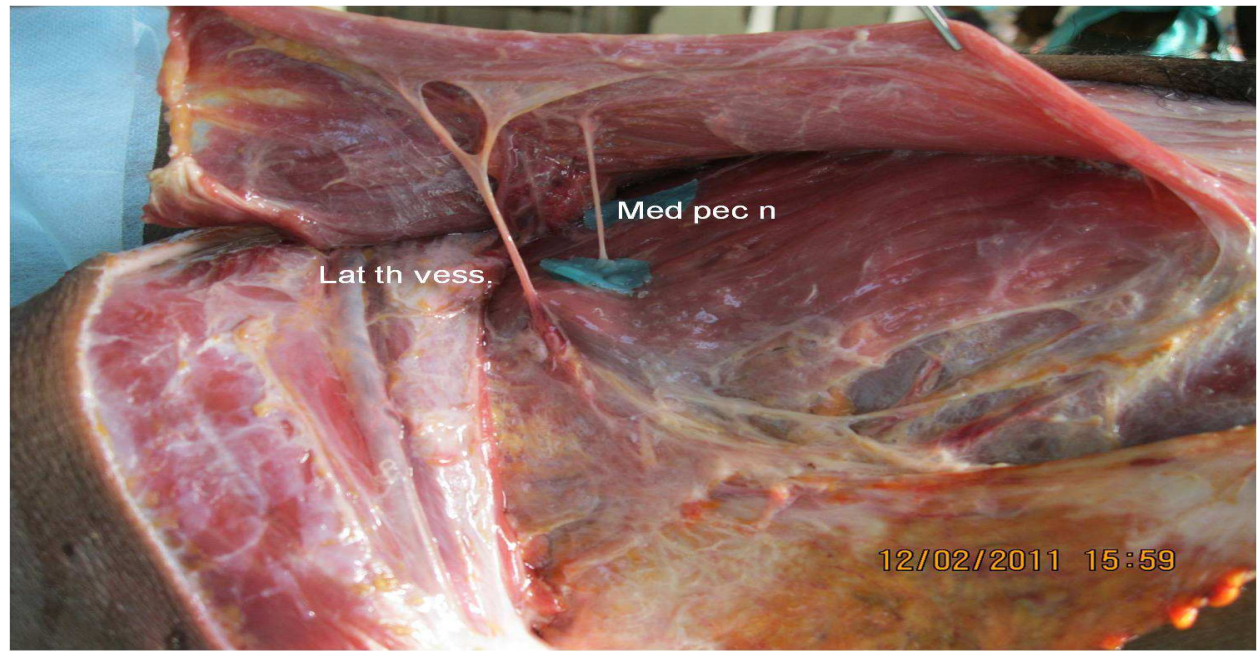

Fig-2: Relationship of medial \&lateral pectoral nerves

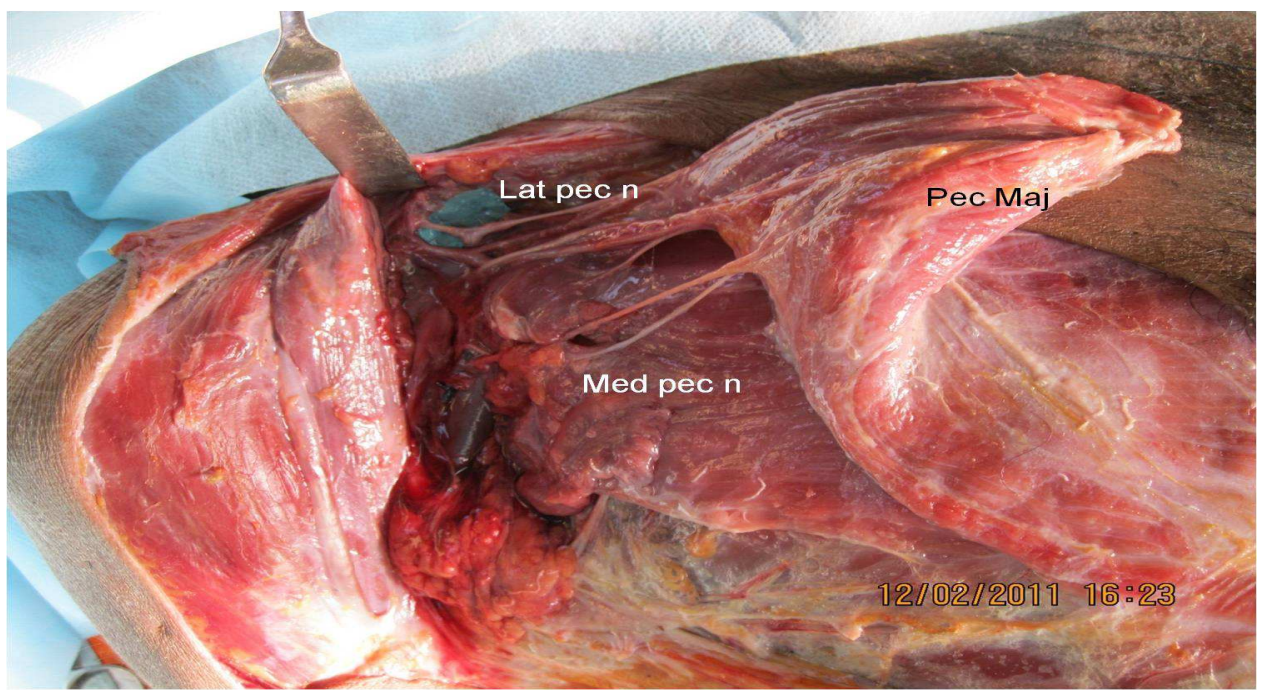

Fig-3: Medial pectoral nerve piercing pec.minor-supplying pec.major on its undersurface 


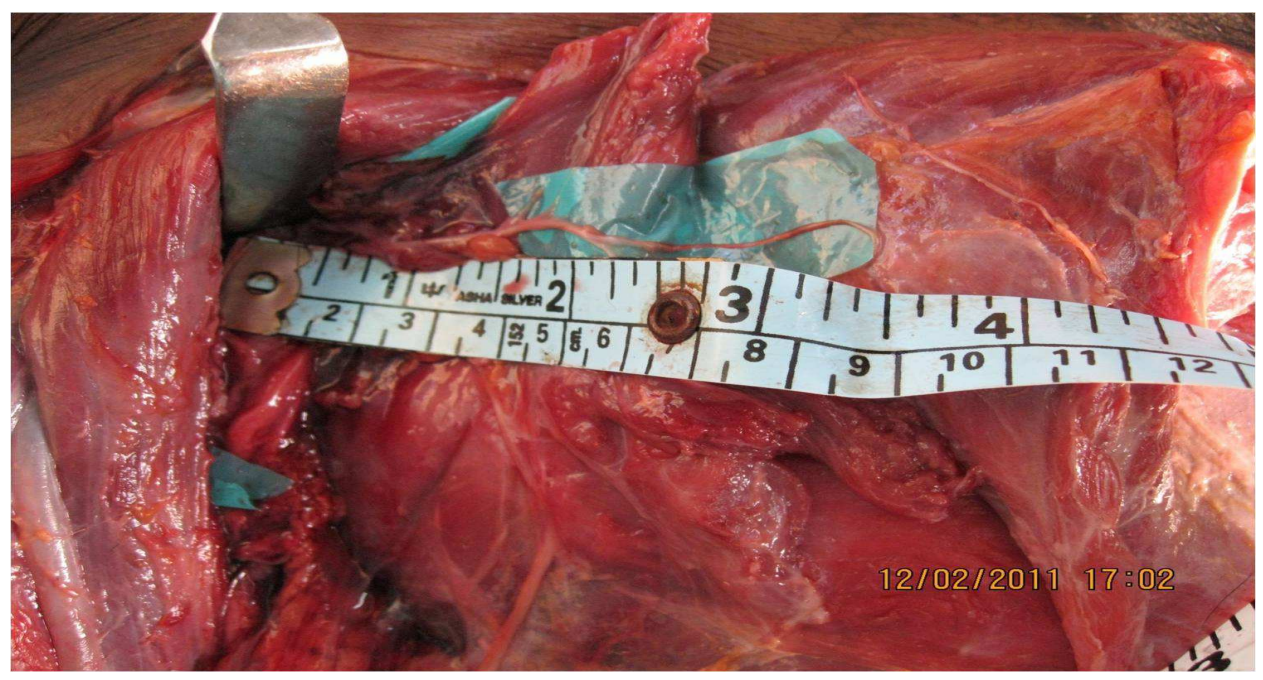

Fig-4: length of medial pectoral nerve approx.8cms

Inclusion Criteria: All the cadavers dissected were male, age ranging from 35 - 60 years

Exclusion Criteria: Females and children were excluded from the study.

\section{Results}

In all dissections, the lateral pectoral nerves showed a constant course parallel to thoracoacromial vessels. The medial pectoral nerves deep aspect of pectoralis minor as a single trunk and gave 1 to 2 branches to pectoralis major on its under surface. Our dissection revealed Ansa formation between lateral and medial pectoral nerves. Average length of medial pectoral nerve without proximal intraneural and distal intramuscular dissection was about $80 \mathrm{~mm}$ and a mean diameter ranging between 1.4 and $2.7 \mathrm{~mm}$ with defined component spinal inputs from C8 and T1(Fig 4) Medial pectoral nerve can reach musculocutaneous nerve from lateral cord and cannot reach axillary nerve. Fascicular count is not done.

\section{Discussion}

Traumatic brachial plexus injuries represent a significant public health problem affecting more than $1 \%$ of multi-trauma victims and nearly $5 \%$ of motorcycle accidents [1]. The use of nerve transfer procedures has become well established, providing peripheral nerve surgeons with multiple treatment options for proximal and intraplexus injuries. These approaches utilize both intraplexus and extraplexus motor donors such as the MPN. Other utilized nerves include the intercostals, thoracodorsal nerve, long thoracic nerve, phrenic nerve, distal accessory nerve, ipsilateral C7 root, contra lateral C7 root, and the suprascapular nerve $[2,3,4]$. Although well described in the literature, the utility of the MPN as a donor nerve remains controversial $[5,6,7]$ due to the limitations in length, inappropriate diameter match, and potential loss of shoulder internal rotation.

The MPN arises from the medial cord of the brachial plexus via the $\mathrm{C} 8-\mathrm{T} 1$ ventral rami. This nerve may originate from the anterior division of the inferior trunk [8]. It then travels posterior to the first part of the axillary artery and unites anterior to this artery to form a loop (ansa pectoralis) with a branch from the lateral pectoral nerve [8]. The MPN next innervates the pectoralis minor muscle and normally pierces this muscle to end in 2 or 3 branches that then innervate the pectoralis major muscle. Variations of the MPN are infrequent. This nerve may supply twigs to the anterior belly of the deltoid muscle and to the acromioclavicular joint. Fibers from the MPN innervating the pectoralis major may travel along the inferior border of the pectoralis minor instead of piercing it [9]. One case has been described in which the MPN joined the intercostobrachial nerve [10].

However, $73 \%$ are composed of fibers from C8 and T1, alternatively $\mathrm{C} 8$ alone or $\mathrm{T} 1$ alone. As an intraplexus motor donor, the MPN has an increased number of donor motor axons. Its main trunk contains approximately 1,100 to 2,100 motor fibers [11]. Cadaver studies show a surgically obtainable length of up to $78 \mathrm{~mm}$ and a mean diameter ranging between 1.4 and $2.7 \mathrm{~mm}$, with defined component spinal inputs from $\mathrm{C} 8$ and $\mathrm{T} 1[12,13]$. 
Transfer of the MPN to either the MCN or axillary nerve is well documented in the literature following nonbirth injury. Samardzic et al [14] described 25 patients aged 9-55 years who underwent neurotization from the MPN to the MCN or axillary nerve. More than $80 \%$ in both groups had useful functional recovery. Merrell et al [15] in a 2001 case series and metaanalysis, reported using MPN transfer in 1 patient out of a total of 35 explorations.

The ages of all patients in the case series ranged from 4 months to 67 years, with a median age at time of surgery of 28 years. Two other publications are mentioned in the meta-analysis, and they discuss one successful MPN to MCN transfer and another successful group of transfers in which MPN was used.

Others have transferred the MPN to the musculocutaneous nerve for repair of obstetric upper plexus injuries with excellent functional results [16].

In 1993, Brandt \& Mackinnon reported use of MPN as an improved alternative over nerve grafting from the root level which was standard at the time for Upper BPI. This technique used MPN in transfer to MCN distal to branch of coracobrachialis.

The success of more distal transfers of fascicles from median nerve and ulnar nerve to muscular branches of MCN has limited the need to rely on more proximal donor nerves. Situations may still arise that require the use of more traditional donors. In addition to reconstruction of MCN the MPN has been used for reconstruction of Proximal Spinal Accessory nerve, long thoracic nerve $\&$ axillary nerve.

Transfer of MPN and TDN compared favorably to transfer of ICN for the MCN in a 62 patient cohort followed for 3 years. More than 33\% of MPN fail to reach the MCN by $15 \mathrm{~mm}$ mean distance and have a diameter discrepancy of 2.5:1. 85\% functional recovery for the $\mathrm{MCN}$ and $82 \%$ functional recovery for the AXN using the medial pectoral nerve for neurotisation in 25 patients [17].

\section{Conclusion}

Medial pectoral nerve can reach musculocutaneous nerve from lateral cord and cannot reach axillary nerve and can be used as a donor for neurotisation in partial plexus injuries. Use of medial pectoral nerve as a donor may not result in complete pectoral dysfunction.
Funding: Nil, Conflict of interest: None initiated, Permission from IRB: Yes

\section{References}

1. Midha R. Epidemiology of brachial plexus injuries in a multitrauma population. Neurosurgery.1997;40:118289. doi: 10.1097/00006123-199706000-00014.

2. Colbert S, Mackinnon S. Posterior approach for double nerve transfer for restoration of shoulder function in upper brachial plexus Hand (N Y). 2006 Dec;1(2):71-7. doi: 10.1007/s1 1552-006-9004-4.

3. Humphreys DB, Mackinnon SE. Nerve transfers. Oper Tech Plast Reconstr Surg. 2002;9:89-99. doi: 10.1053/otpr.2003.S1071-0949(03)00057-X.

4. Mackinnon SE. Preliminary results of double nerve transfer to restore elbow flexion in upper type brachial plexus palsies. Plast Reconstr Surg. 2006;118:1273. doi: 10.1097/01.prs.0000238220.56097.4e.

5. Park TS. Medial pectoral nerve transfer. J Neurosurg Pediatr.2009;3:34546.doi:10.3171/2008.12.PEDS08370

6. Shin AY, Spinner RJ, Bishop AT. Nerve transfers for brachial plexus injuries. Oper Tech Orthopaedics 2004; 14(3)199-212

7. Wellons JC, Tubbs RS, Pugh JA, Bradley NJ, Law $\mathrm{CR}$, Grabb PA. Medial pectoral nerve to musculocutaneous nerve neurotization for the treatment of persistent birth-related brachial plexus palsy: an 11-year institutional experience. J Neurosurg: Ped. 2009;3: 348353.doi:10.3171/2008.11.PEDS08166.

8. Loukas M, Grabska J, Tubbs RS, Indies RG, Usa U: An unusual union of the intercostobrachial and medial pectoral nerve. Folia Morphol (Warsz) 66:356-59, 2007

9. Bergman RA, Thompson SA, Afifi AK, Saadeh FA: Compendium of Human Anatomic Variation. Munich: Urban \& Schwarzenberg, 1988.

10. Loukas M, Louis RG, Fitzsimmons J, Colborn G: The surgical anatomy of the ansa pectoralis. Clin Anat 19:685-693, 2006.

11. Shin AY, Spinner RJ, Bishop AT. Nerve transfers for brachial plexus injuries. Oper Tech Orthopaedics 2004;14(3):199-212. 
12. Hansasuta A, Tubbs RS, Grabb PA. Surgical relationship of the medial pectoral nerve to the musculocutaneous nerve: a cadaveric study. Neurosurgery. 2001;48:203-207

13. Lee K-S. Anatomic variation of the spinal origins of lateral and medial pectoral nerves. Clin Anat.2007;Nov: 20 (8):915-18. doi: 10.1002/ca.20556.

14. Samardzic M, Grujicic D, Rasulic L, Bacetic D. Transfer of the medial pectoral nerve: myth or reality? Neurosurgery. 2002;50:1277-82.

15. Merrell GA, Barrie KA, Katz DL, Wolfe SW: Results of nerve transfer techniques for restoration of shoulder and elbow function in the context of a meta- analysis of the English literature. J Hand Surg [Am] 26:303-14, 2001

16. Blaauw G, Slooff ACJ. Transfer of pectoral nerves to the musculocutaneous nerve in obstetric upper brachial plexus palsy. Neurosurgery. 2003;53:338-42. doi:310.1227/1201.NEU.0000073420.0000066113. 000 0073466.

17. Wellons JC, Tubbs RS, Pugh JA, Bradley NJ, Law $\mathrm{CR}$, Grabb PA. Medial pectoral nerve to musculocutaneous nerve neurotization for the treatment of persistent birth-related brachial plexus palsy: an 11-year institutional experience. J Neurosurg: Ped. 2009;3:34853. doi: 10.3171/2008.11.PEDS08166.

\section{How to cite this article?}

Srijana M., Srikanth R. Cadaver dissection study of the pectoral nerves for feasibility in brachial plexus injuries. Int $J$ Med Res Rev 2016;4(11):2059-2063.doi:10.17511 /ijmrr. 2016.i11.27. 